\title{
Morphology-property-relationship of thermo-mechanically graded self-reinforced polypropylene composites
}

Cite as: AIP Conference Proceedings 1593, 776 (2014); https://doi.org/10.1063/1.4873890

Published Online: 17 February 2015

H.-P. Heim, B. Rohde, and A. Ries

\section{ARTICLES YOU MAY BE INTERESTED IN}

A framework for the computer-aided planning and optimisation of manufacturing processes for components with functional graded properties

AIP Conference Proceedings 1593, 762 (2014); https://doi.org/10.1063/1.4873887

Optimization of thermomechanical processes for the functional gradation of polymers by means of advanced empirical modeling techniques

AIP Conference Proceedings 1593, 766 (2014); https://doi.org/10.1063/1.4873888

Meet the Next Generation of Quantum Analyzers And Join the Launch Event on November 17th

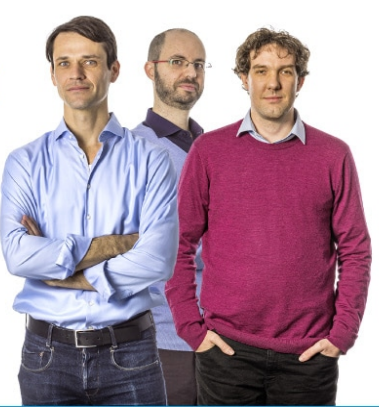




\title{
Morphology-Property-Relationship of Thermo-Mechanically Graded Self-Reinforced Polypropylene Composites
}

\author{
H.-P. Heim, B. Rohde, A. Ries \\ Institute for Materials Engineering - Polymer Technology, University of Kassel, Germany - heim@uni-kassel.de; \\ bjoern.rohde@uni-kassel.de; angela.ries@uni-kassel.de
}

\begin{abstract}
In this paper the relationship between different composite morphologies and their mechanical properties is to be investigated. By manufacturing two different tape-based polypropylene composites in a compression moulding process, four varying degrees of compaction will be generated. The morphological structure is analyzed using confocal laser light microscopy and wet chemically etched specimen cross-sections. The etching process removes the amorphous phase in the polymer, making the macromolecular orientations and superstructures visible in the reinforcement tapes. The findings of the morphological analysis will be transferred to the results of mechanical investigations.
\end{abstract}

Keywords: Thermo-mechanical gradation, self-reinforced polypropylene composites, impact testing, morphology investigations, wet chemical etching, confocal laser-light microscopy.

\section{INTRODUCTION}

Self-reinforced composite materials based on polypropylene (SR-PP) consist of layered semifinished textile products [1]. In most cases, these textile systems are applied in form of tape fabrics or fleeces. Due to the fact that self-reinforced PP-composites do not contain foreign reinforcement fibres, such as glass, carbon or aramide, these composites are called monomaterial systems. Their reinforcement fibres are identical to their matrix phase [2]. The advantages of self-reinforced PP-composites include very good recycling properties and predestination for being used in light-weight applications owing to the low density of polypropylene of $0.91 \mathrm{~g} / \mathrm{cm}^{3}$ [3]. Due to 5-6 fold higher mechanical properties of injection moulded PP, i.e., stiffness, strength and impact resistance, these composite materials are excellently suited for applications which require high crash absorption properties [4].

The self-reinforcement is based on the principle of a macromolecular orientation in the polymer. This orientation can be achieved in two steps. In the melt liquid polymer phase the orientation of the macromolecules is generated by flow-induced stretching and shear deformations which result from a local increase of the flow speed. In this stage, the socalled shish-kebab superstructure is generated [5]. In the second step, an ensuing solid phase deformation usually increases the macromolecular orientation in the amorphous polymer phase. This is achieved by means of a conventional cold drawing process (plastic deformation) in a temperature range below melt temperature.

The processing of layered, semi-finished textile systems into thermo-mechanically graded composites is carried out in a precision hot press using a special compression moulding tool [6]. By setting different temperatures in this tool and varying pressing forces which result from the tool geometry, four different degrees of compaction are generated in the composite. The degree of compaction primarily depends on the temperature, which influences the composite morphology. However, self-reinforced textiles react very sensitive to temperature. On the one hand, a minimum temperature is necessary to generate the matrix phase by means of selective melting of the reinforcement fibre surfaces. On the other hand, the orientation can be destroyed by selecting a temperature that is too high, because it would trigger relaxation mechanisms.

\section{EXPERIMENTAL}

Thermo-mechanical processing of self-reinforced polypropylene composites in a compression moulding process

Two different tape fabrics were compacted into layered composites in the experiments presented in this section. A total of 16 fabric layers of the textiles listed in Table 1 were layered and fixated in a tenter frame to avoid thermically induced relaxation mechanisms. The essential difference between the two textiles lies in their structures. The co-extruded plain weave tape fabric named Pure (Lankhorst, Netherlands) has many marginal layers that were extruded onto the outer edges. These layers have a $10^{\circ} \mathrm{C}$ lower melt temperature than the internal, highly oriented core. Therefore, it is fundamentally safer to process in a hot compaction or compression moulding process, and reacts significantly less sensitive to temperature and pressure. For purposes of comparison, a second, semifinished textile product made of mono-extruded tape fabric that is highly affine to gradation was added. It is named SG30/30 (Bonar, Belgium). This soot-tinted 
geotextile with a 2/1 twill weave has lower mechanical values, but is an inexpensive and extremely gradable product alternative.

TABLE 1 - Mechanical properties of the employed tape fabrics $[7,8]$

\begin{tabular}{|c|c|c|c|c|}
\hline Product & $\begin{array}{c}\text { Max. } \\
\text { Elongation } \\
\% \\
\% \\
\end{array}$ & $\begin{array}{c}\text { Tensile } \\
\text { Strength } \\
\text { Tapes } \\
{\left[\mathbf{N} / \mathbf{m m}^{2}\right]}\end{array}$ & $\begin{array}{c}\text { Tensile } \\
\text { Strength } \\
\text { Fabric } \\
{[\mathrm{kN} / \mathrm{m}]} \\
\end{array}$ & $\begin{array}{c}\text { Area } \\
\text { Weight } \\
{[\mathrm{g} / \mathrm{m}]}\end{array}$ \\
\hline & 6 & 500 & - & 105 \\
\hline SG30/30 & 17 & - & 30 & 124 \\
\hline
\end{tabular}

The first step in the initiated compression moulding process is a pre-tempering of the semi-finished textile products, which are clamped in a tenter frame, using an upstream IR-preheating sequence. Somewhat delayed, a $2 \mathrm{~mm}$ thick aluminum sheet is placed between the IR radiators and the textile layers to be heated, in order to optimise the gradation. This way, the textile layers located underneath are partially masked from preheating temperatures (here, from a half-sided IR radiator panel). In turn, this strengthens the effect of thermo-mechanical gradation in the ensuing compression moulding process.

After the preheating sequence has been completed, the tenter frame with the preheated textiles is automatically placed in the pressing unit (clamping surface $350 \times 350$ $\mathrm{mm}^{2}$ ). The compression mould, which is preheated to the pressing temperature, closes and carries out the hot compaction of the layered composites using a combination of heat and pressure. As previously mentioned, the here presented experiments are part of a modified consolidation process which aims to thermomechanically grade the later composite properties. For this reason, two different press temperatures are used for the thermal gradation. The thermal gradation here is analogous to that in the preheating sequence and is restricted to the left $\left(\mathrm{T}_{1}\right)$ and right $\left(\mathrm{T}_{2}\right)$ tool halves.

Furthermore, different levels of pressure are induced on the surface of the component, and are derived from the simple, three dimensional triangular geometry of the tool. The level of pressure on the slants of the triangular geometry, caused by an open angle of $110^{\circ}$, is approximately $30 \%$ lower $\left(p_{2}\right)$ than that on the orthogonal tool areas $\left(\mathrm{p}_{1}\right)$.

Thus, there are 4 different gradation zones per composite. These result from a combination of two different temperatures $\left(T_{1}, T_{2}\right)$ achieved by partial masking in the IR preheating sequence, and the two different temperature settings in the compression mould that has two different pressure levels $\left(\mathrm{p}_{1}, \mathrm{p}_{2}\right)$ in the triangular geometry of the tool.

A five minute, isobaric cooling sequence concludes the processing procedure. The tool is cooled to $40^{\circ} \mathrm{C}$ to remove the tenter frame and later the composite from the mould.
The employed processing parameters as well as the designation of sample positions are shown in Fig. 1 and Table 2.

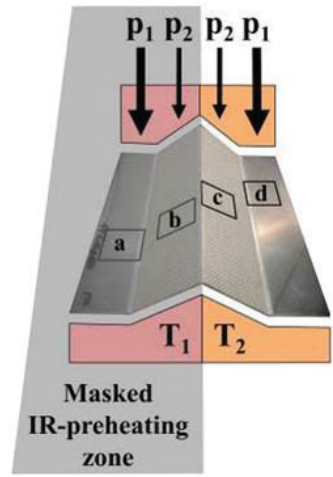

FIGURE 1 - Compression moulded Pure Composite and sample positions a to $\mathrm{d}$ with according processing parameter (masking during IR preheating sequence, $\mathrm{T}_{1}$ and $\mathrm{T}_{2}$ are the tool temperatures and $\mathrm{p}_{1}$ and $\mathrm{p}_{2}$ the press pressures).

TABLE 2 - Processing Parameter and Designated Sample Positions of the Thermo-Mechanically Graded Composite

\begin{tabular}{|c|c|c|c|c|}
\hline & & & & $\begin{array}{l}\text { Sample } \\
\text { Position }\end{array}$ \\
\hline \multirow{3}{*}{$\cong$ 苞 } & IR-Temp. & $\mathrm{T}_{\mathrm{IR}}\left[{ }^{\circ} \mathrm{C}\right]$ & 134 & \\
\hline & IR-time & $\mathrm{t}_{\mathrm{IR}}[\mathrm{sec}]$ & 117 & \\
\hline & Masking Time & $\mathrm{t}_{\text {mask }}[\mathrm{sec}]$ & 19 & $a, b$ \\
\hline \multirow{5}{*}{ 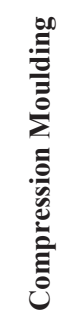 } & Pressing Time & $\mathrm{t}_{\text {comp }}[\mathrm{sec}]$ & 165 & \\
\hline & $\begin{array}{c}\text { Temperature } / \\
\text { Pressure }\end{array}$ & $\begin{array}{l}\mathrm{T}_{1}\left[{ }^{\circ} \mathrm{C}\right] / \\
\mathrm{p}_{1}[\mathrm{MPa}]\end{array}$ & $\begin{array}{c}197 / \\
5.5\end{array}$ & $\mathrm{a}$ \\
\hline & $\begin{array}{c}\text { Temperature / } \\
\text { Pressure }\end{array}$ & $\begin{array}{l}\mathrm{T}_{1}\left[{ }^{\circ} \mathrm{C}\right] / \\
\mathrm{p}_{2}[\mathrm{MPa}]\end{array}$ & $\begin{array}{c}197 / \\
3.9\end{array}$ & $b$ \\
\hline & $\begin{array}{c}\text { Temperature } / \\
\text { Pressure }\end{array}$ & $\begin{array}{l}\mathrm{T}_{2}\left[{ }^{\circ} \mathrm{C}\right] / \\
\mathrm{p}_{2}[\mathrm{MPa}]\end{array}$ & $\begin{array}{c}187 / \\
3.9\end{array}$ & $\mathrm{c}$ \\
\hline & $\begin{array}{c}\text { Temperature } / \\
\text { Pressure }\end{array}$ & $\begin{array}{l}\mathrm{T}_{2}\left[{ }^{\circ} \mathrm{C}\right] / \\
\mathrm{p}_{1}[\mathrm{MPa}]\end{array}$ & $\begin{array}{c}187 / \\
5.5\end{array}$ & $\mathrm{~d}$ \\
\hline
\end{tabular}

In order to determine the thermo-mechanically graded properties, on specimen a to $\mathrm{d}$ instrumented $10 \mathrm{~J}$ impact tests according to DIN EN ISO 6603-2 were carried out.

\section{Confocal Laser Light Microscopy}

Using a high-resolution, confocal laser light microscope makes it possible to examine the fine structure of the composite morphology closely. This light microscopy method is similar to scanning electron microscopy. A laser beam scans the surface of the sample in Z-direction, so that the samples' surface is recorded three dimensionally.

Differential interference contrasting enables a clearer emphasis of the composite topography. An extensive preparation of the surface, i.e. sputtering, is not necessary. 
The preparation of samples from self-reinforced layered composites is carried out using a low-speed cutting machine. A diamond saw blade cuts the consolidated composite precisely into handy sized samples. A low rotation speed, low feed and cooling with water significantly reduce the thermal load on the sample, so as not avoid it influencing the composite structure. A subsequent, multi-step grinding process with a grain size up to 4000 has proven to be exceptionally successful for the following treatment step.

In order to enhance the fine structure of the composite cross-sections, the microscope samples are subjected to a two day, wet chemical etching process at room temperature $\left(20^{\circ} \mathrm{C}\right)$. The etchant is especially suitable for polypropylene and is composed of phosphoric acid, sulphuric acid and potassium permanganate [9]. During the etching process, the softer, amorphous polymer phase of the layered composite is removed [10], exposing the crystalline phase.

\section{RESULTS AND DISCUSSION}

The Morphology of Self-Reinforced PP Composite Systems

Following, the compaction degrees of the layered composites Pure and SG30/30 are to be analysed using microscopy. Table 3 shows images taken using a confocal laser light microscope with a magnification of 1000-fold. All four grading positions are shown for both tape fabric composite structures. These differ from one another in regards of the processing conditions pressing temperature and pressure.

In the case of the co-extruded material system Pure, the tapes in the direction of stretching can be made out very well; especially in positions $b$ to $d$ they are characterised by a regular, pronounced texture that is very similar to the shish-kebab structure [5] so typical for self-reinforcement. Also, the marginal co-extrusion layers that were extruded onto can be seen very clearly. Due to the high processing temperature in combination with high pressure in position a, less pronounced crosssections occur in the composite. Moreover, the characteristic texture of the tapes in the direction of stretching is no longer identifiable.

The detailed images of the mono-extruded composite system SG30/30 can also be distinguished by their straight texture in the direction of stretching. In contrast to Pure, the SG30/30 layered composite displays more sensitive behavior regarding press temperature and pressure. Accordingly, due to a high temperature and pressure, position a shows an unidentifiable tape configuration that is dominated by the development of spherolithic and transcrystalline [11] structures. The high influence of the pressing force becomes apparent in the by far cooler sample positions $\mathrm{c}$ and $\mathrm{d}$. The reduction of pressure in position c reduces the entry of temperature in the textile layers, resulting in essentially thicker tape fabric crosssections.

TABLE 3 - Images of the positions a to $d$ of the tape composites Pure and SG30/30 taken using a confocal laser light microscope

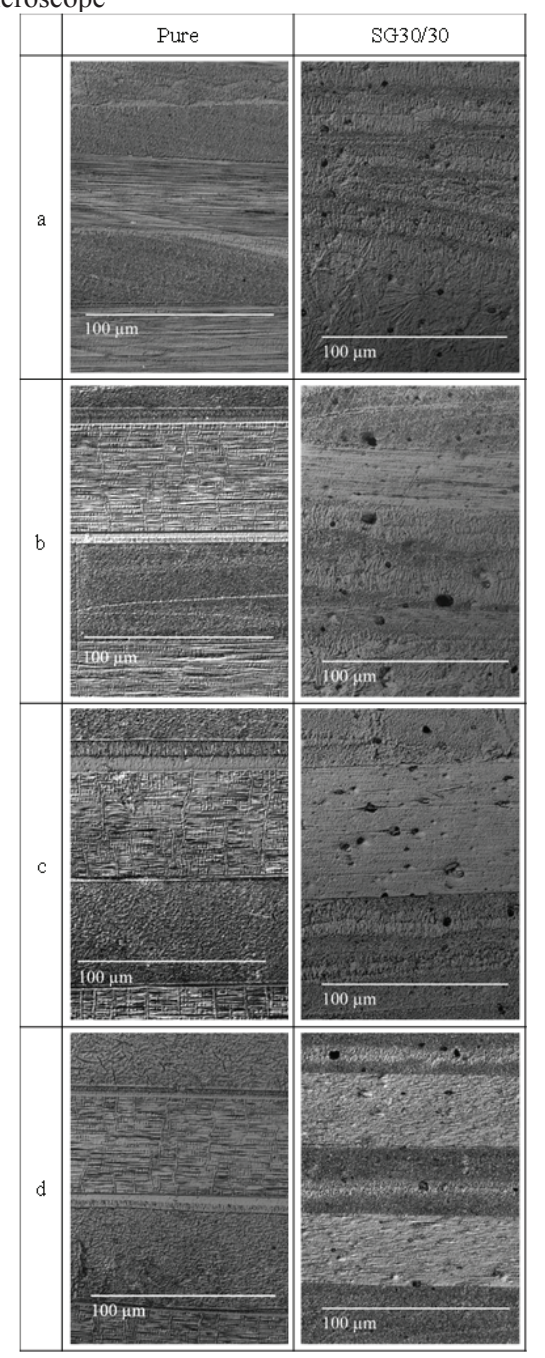

Mechanical Characterisation Using $10 \mathrm{~J}$ Impact Tests So as to be able to make conclusions regarding the influence of processing on the real behavior of the component, the impact properties of Pure and SG30/30 composites is depicted in Fig. 2 and 3.

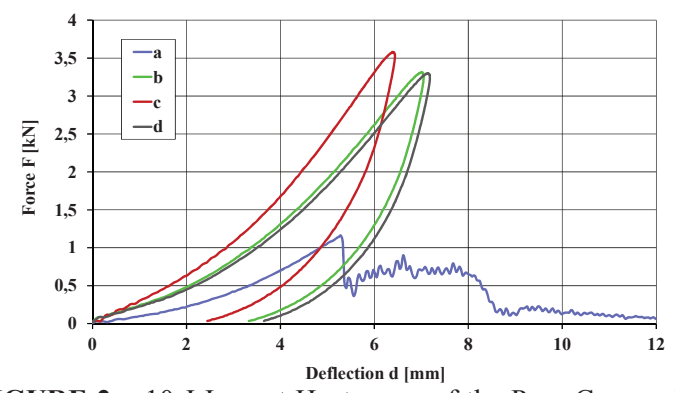

FIGURE 2 - 10 J-Impact Hystereses of the Pure Composite with Sample Positions a to d. 


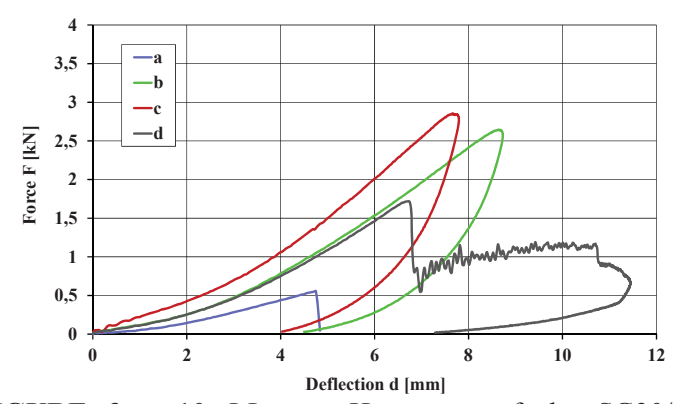

FIGURE 3 - 10 J-Impact Hystereses of the SG30/30 Composite with Sample Positions a to d.

It is evident that, in comparison, the co-extruded Pure displays significantly higher strengths and stiffnesses than the mono-extruded SG30/30 composite, except for sample a. Here, the processing conditions were very high $\left(\mathrm{T}_{1}=197{ }^{\circ} \mathrm{C}\right.$ and $\left.\mathrm{p}_{1}=5.5 \mathrm{MPa}\right)$, leading to material failure in both materials upon impact. The SG30/30 composite, in contrast, may have lower strengths, but still displays a fundamentally higher thermo-mechanical gradation potential due to the higher variance of the hystereses.

In addition to the morphological and mechanical tests, the tapes were measured across the complete composite cross-sections and compared with the maximum impact forces, compare Fig. 4 and 5.

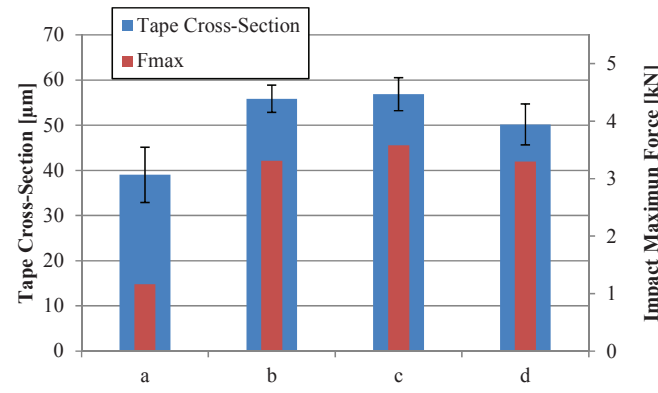

FIGURE 4 - 10 J-Impact Maximum Forces in Correlation to Pure Tape Cross-Sections

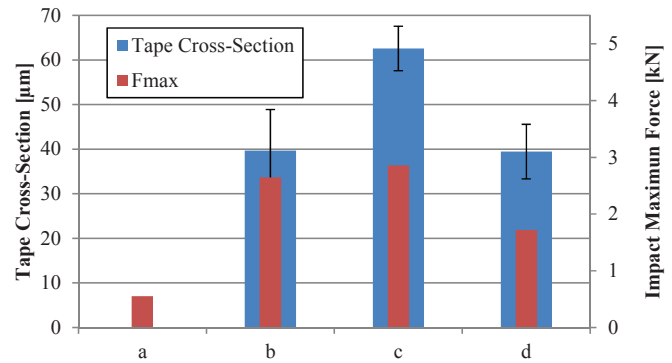

FIGURE 5 - $10 \mathrm{~J}$-Impact Maximum Forces in Correlation to SG30/30 Tape Cross-Sections

As Fig. 4 clearly illustrates, the tape thicknesses of the graded Pure composite correlate very well with the determined maximum impact forces. Co-extruded composite systems react less sensitive to temperature and pressure influences, as the diagram shows in positions $\mathrm{b}$ to $\mathrm{d}$.

In comparison, the mono-extruded composite system SG30/30 reacts significantly more sensitive to varying processing settings, see Fig. 5.

Due to the high temperature and pressure influences, it is not possible to measure the tapes of SG30/30 in position a. The temperature and pressure differences in the individual grading zones make it possible to set specifically composite properties, which essentially depend upon the tape thickness.

\section{CONCLUSION}

In sum, a visible influence of the processing settings on the final mechanical properties of self-reinforced composite systems was verified. In particular monoextruded systems, such as SG30/30, display a much higher potential for thermo-mechanical gradation due to variations of pressing temperatures and forces.

\section{ACKNOWLEDGMENTS}

This paper is based on investigations carried out in the collaborative research centre CRC/TRR 30, subproject A5, which is kindly supported by the German Research Foundation (DFG).

\section{REFERENCES}

1. P.J. Hine; I.M. Ward; N.D. Jordan; R. Olley; D.C. Bassett Polymer 2003, 44, 1117-1131.

2. I.M. Ward; P.J. Hine Polymer 2004, 45, 1413-1427.

3. T. Peijs materialstoday 2003, 6, 30-35.

4. H.-P. Heim, A. Ries, A.K. Bledzki in SEICO 11 Proceedings, Paris, 2011, CD.

5. G.W. Ehrenstein, Polymerwerkstoffe, Carl Hanser Verlag, München Wien, 1999.

6. D. Paßmann, PhD Thesis, University of Kassel, 2009.

7. N.N.: Technical data sheet, Pure, Lankhorst, NL-8600 AE Sneek - Netherlands.

8. N.N.: Technical data sheet, SG 30/30, Bonar TF, B9240 Zele - Belgium.

9. A. Breining, G.W. Ehrenstein, J. Varga Materialprüfung 1997, 3, 81-85.

10. H.-P. Heim, B. Rohde, A. Ries in 1st International Conference on Thermo-Mechanically Graded Materials, Proceedings, Kassel, 2012, 247-252, ISBN 978-3942267-58-8.

11. N.D. Jordan; D.C. Bassett; R.H. Olley; P.J. Hine; I.M. Ward Polymer 2003, 44, 1133-1143. 